Introduction: Combinations of 5 -fluorouracil/leucovorin (5-FU/LV) with oxaliplatin (FOLFOX) or irinotecan (FOLFIRI) are part of standard treatments for metastatic colorectal cancer (mCRC). For these molecules, the impact of a low relative dose intensity (RDI) on survival is not sufficiently known in real-life.

Material and methods: Data were collected retrospectively from patients treated in our center for an unresectable mCRC with FOLFOX or FOLFIRI as a first-line treatment. To study the impact on progression-free survival (PFS) and overall survival (OS), patients were divided into high and low RDI according to the median RDI of 5-FU on one end, and the median RDI of oxaliplatin or irinotecan (OXA-IRI) on the other.

Results: In our population of 75 patients, the median age was 67.1 years and $77 \%$ of patients were treated with FOLFIRI. Patients with high RDI for OXA-IRI had better PFS compared to patients with low RDI (hazard ratio [HR], 0.58; $p=0.03$ ). There was no statistically significant difference in PFS for patients with high RDI for 5-FU (HR, 0.66; $p=0.09$ ). No difference was found in overall survival according to the RDI of OXA-IRI (HR, 0.72; $p=0.18)$ or 5 -FU (HR, 0.77; $p=0.29$ ). RDI had no significant impact on toxicities.

Conclusions: Our analysis suggests that a low RDI of oxaliplatin and irinotecan has a negative effect on PFS. RDI had no significant effect on OS in our cohort. The clinical benefit of maintaining high RDI in these patients appears low.

Key words: colorectal cancer, relative dose intensity, chemotherapy, survival, real-life.

Contemp Oncol (Pozn) 2020; 24 (3): 150-156 DOI: https://doi.org/10.5114/wo.2020.100222

\section{Survival and relative dose intensity of 5-fluorouracil, oxaliplatin and irinotecan in real-life treatment of metastatic colorectal cancer}

\author{
Ilfad Blazevic ${ }^{1}$, Willy Vaillant ${ }^{2}$, Maud Basso ${ }^{2}$, Karine Salignon ${ }^{2}$
}

${ }^{1}$ Medical Oncology Department, University Cancer Institute Toulouse Oncopole, Toulouse, France

${ }^{2}$ Medical Oncology Department, Auch Hospital Center, Auch, France
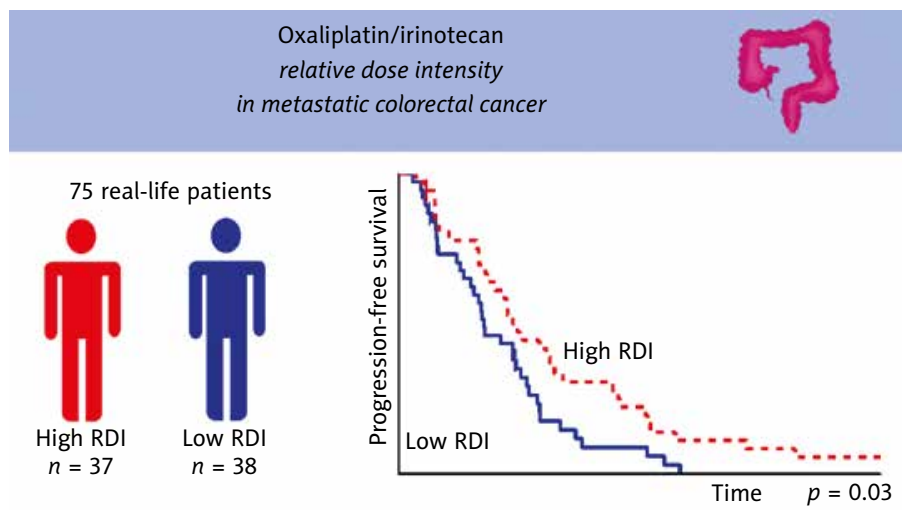

\section{Introduction}

In metastatic colorectal cancer ( $\mathrm{mCRC}$ ) with unresectable metastases, the combination of 5-fluorouracil/leucovorin (5-FU/LV) with oxaliplatin (FOLFOX regimen) or irinotecan (FOLFIRI regimen) is part of the first-line standard treatment that improved patient survival when compared to 5-FU/LV administered alone [1-4]. The use of monoclonal antibodies against VEGF and EGFR has also proved beneficial in this situation [5].

These treatments are intended to be administered at a certain dose and regimen. However, due to the onset of toxicities, it is common in clinical practice to make dose reductions or delay the administration of these molecules, which has the consequence of decreasing the relative dose intensity (RDI) $[6,7]$. In many cancers, low chemotherapy RDI is associated with decreased disease control and survival [8-11]. With regard to $\mathrm{mCRC}$, certain retrospective analyses of patients treated with FOLFOX or FOLFIRI have highlighted a link between survival and RDI of oxaliplatin and irinotecan [12, 13]. For 5-FU, one study has shown a possible link between RDI and response rate [14]; however, these results were not confirmed in a second trial when 5-FU was combined with LV [15]. In these studies, data resulted from clinical trials. As far as is known, in real-life, no study has shown a negative impact on survival of a low RDI of oxaliplatin, irinotecan or 5-FU in patients treated with FOLFOX or FOLFIRI $[16,17]$.

The objective of this analysis is to determine, in real-life, the impact on progression-free survival (PFS) and overall survival (OS) of RDI of 5-FU, oxaliplatin and irinotecan in patients treated for a MCRC, as part of FOLFOX and FOLFIRI regimens. 


\section{Material and methods}

\section{Patients}

Data were collected from patients treated between September 2008 and January 2019 with FOLFOX or FOLFIRI as a first-line treatment in our center for a histologically proven mCRC with unresectable metastases. Some patients were treated with bevacizumab, cetuximab, panitumumab or a colorectal resection. Patients treated with capecitabine or who received less than 2 cycles of chemotherapy were not included. Co-morbidities were assessed by the Charlson index [18]. This work was done in accordance with the Declaration of Helsinki and the General European Data Protection regulation (number 2016/679). The methodology was validated by the Data Protection Officer of our center.

\section{Treatment and dose intensity}

Oxaliplatin was administered at a planned dose of $85 \mathrm{mg} / \mathrm{m}^{2}$, irinotecan at $180 \mathrm{mg} / \mathrm{m}^{2}$ and leucovorin at $400 \mathrm{mg} / \mathrm{m}^{2}$. 5-FU contained a bolus of $400 \mathrm{mg} / \mathrm{m}^{2}$ followed by an infusion of $2400 \mathrm{mg} / \mathrm{m}^{2}$ over 46 hours. Bevacizumab was administered at $5 \mathrm{mg} / \mathrm{kg}$, cetuximab at $400 \mathrm{mg} / \mathrm{m}^{2}$ in the first cycle, $500 \mathrm{mg} / \mathrm{m}^{2}$ in following cycles and panitumumab at $6 \mathrm{mg} / \mathrm{kg}$ every 2 weeks.

The planned duration of treatment (weeks) corresponded to the number of cycles multiplied by the duration of a cycle, i.e. two weeks. Actual duration of treatment (weeks) was calculated as follows: [(last cycle date) - (first cycle date) + 14] / 7. For a given molecule, planned dose intensity (DI) was obtained by dividing the planned cumulative dose (CD, mg) by the planned duration of treatment (weeks). Actual DI was calculated by dividing the actual CD by the actual duration of treatment. RDI, expressed as a percentage, corresponded to the ratio between the actual and the planned DI.

\section{Study groups}

For each patient, the RDI of 5-FU was calculated and, depending on the case, the RDI of oxaliplatin or irinotecan. Because of the small number of patients receiving oxaliplatin in our cohort, RDIs of oxaliplatin and irinotecan were pooled and studied together (noted OXA-IRI) to increase the statistical power of the analysis. The median $\mathrm{RDI}$ of 5 -FU was $78.3 \%$ (interquartile range [IQR]: 67.486.2). For OXA-IRI, the median RDI was also 78.3\% (IQR: 68.6-86.1). To determine the impact of the RDI of 5-FU and OXA-IRI on survival, the patients were separated according to the median RDI: patients with a high RDI (> 78.3\%) and patients with a low RDI ( $\leq 78.3 \%)$.

\section{Outcomes}

PFS corresponded to the time (months) from the start of treatment to progression or death, regardless of cause. Overall survival was defined as the time (months) from the date of treatment initiation to the date of death from any cause.

\section{Statistical analysis}

Categorical variables were described using number and percentage, while continuous variables were expressed as median and interquartile range. Patient characteristics were compared using the $\chi^{2}$ test or Fisher's exact test for categorical variables, and the Kruskal-Wallis test for continuous variables. Kendall's tau correlation coefficient was used to assess the correlation between the RDI of 5-FU and the RDI of OXA-IRI. OS and PFS were estimated by the Kaplan-Meier method and presented with a 95\% confidence interval for the overall population and by analysis group. Events that did not occur were right-censored. A univariate and multivariate analysis of PFS and OS was performed using the Cox proportional hazards model. The significance level used was 0.05 .

\section{Results}

\section{Patients}

75 patients meeting the inclusion criteria were identified over the study period. The characteristics of the patients at the start of treatment are presented in Table 1. Median age was 67.1 years (IQR: 61.7-75.3) and the majority of patients $(77 \%)$ had undergone colorectal resection surgery before treatment with chemotherapy. There were no statistically significant differences between the groups studied.

\section{Treatment and relative dose intensity}

The characteristics of the treatment are presented in Table 2. Kendall's tau correlation was 0.78 ( $p<0.01$ ), indicating a significant and strong correlation between RDIs of 5-FU and RDIs of OXA-IRI. In other words, the majority of patients who had a low RDI for 5-FU also had a low RDI for OXA-IRI. Patients with a high RDI had a significantly shorter actual duration of treatment compared to patients with a low RDI, for both 5-FU and OXA-IRI.

\section{Survival}

The median follow-up was 17.5 months. In the overall population, the median PFS was 8.9 months (95\% confidence interval [Cl], 7.07-10.65) and the median OS was 17.9 months $(95 \% \mathrm{Cl}, 13.1-31.3)$. We found a statistically significant difference in PFS in favor of patients with a high RDI of OXA-IRI (hazard ratio [HR], 0.58; 95\% Cl, 0.36-0.95; $p=0.03$ ) (Fig. 1). For 5-FU, there was a trend in favor of patients with a high $\mathrm{RDI}(\mathrm{HR}, 0.66 ; 95 \% \mathrm{Cl}, 0.41-1.07$; $p=0.09)$. There was no statistically significant difference in OS for either patients with a high RDI of 5-FU (HR, 0.77; $95 \% \mathrm{Cl}, 0.48-1.25 ; p=0.29$ ) or patients with a high RDI of OXA-IRI (HR, 0.72; 95\% Cl, 0.45-1.17; $p=0.18)$.

\section{Univariate and multivariate analysis of progression-free survival and overall survival}

Univariate and multivariate analysis of progression-free survival and overall survival are presented in Table 3 and Table 4. The presence of the BRAF V600E mutation was associated with an increased risk of progression or death, both in the univariate and the multivariate analysis, while colorectal surgery decreased the risk of progression or death. There was a higher risk of death in patients with poorly differentiated tumors, both in the univariate and 
Table 1. Patient characteristics in the overall population and according to the relative dose intensity (RDI) of 5-fluorouracil (5-FU) and oxaliplatin or irinotecan (OXA-IRI)

\begin{tabular}{|c|c|c|c|c|c|c|c|}
\hline \multirow[t]{2}{*}{ Characteristics } & \multirow{2}{*}{$\begin{array}{c}\text { Overall } \\
n(\%)\end{array}$} & \multicolumn{3}{|c|}{ 5-FU RDI } & \multicolumn{3}{|c|}{ OXA-IRI RDI } \\
\hline & & $\begin{array}{l}\text { Low } \\
n(\%)\end{array}$ & $\begin{array}{l}\text { High } \\
n(\%)\end{array}$ & $p$-value & $\begin{array}{l}\text { Low } \\
n(\%)\end{array}$ & $\begin{array}{l}\text { High } \\
n(\%)\end{array}$ & $p$-value \\
\hline Number of patients & $75(100)$ & $38(51)$ & $37(49)$ & & $38(51)$ & $37(49)$ & \\
\hline Age, years & & & & 1.00 & & & 0.82 \\
\hline$<65$ & $31(41)$ & $16(42)$ & $15(41)$ & & $15(39)$ & $16(43)$ & \\
\hline$\geq 65$ & $44(59)$ & $22(58)$ & $22(59)$ & & $23(61)$ & $21(57)$ & \\
\hline Gender & & & & 0.64 & & & 0.35 \\
\hline Male & $45(60)$ & $24(63)$ & $21(57)$ & & $25(66)$ & $20(54)$ & \\
\hline Female & $30(40)$ & $14(37)$ & $16(43)$ & & $13(34)$ & $17(46)$ & \\
\hline ECOG PS & & & & 0.33 & & & 0.09 \\
\hline $0-1$ & $57(76)$ & $26(68)$ & $31(84)$ & & $25(66)$ & $32(86)$ & \\
\hline $2-3$ & $12(16)$ & $8(21)$ & $4(11)$ & & $8(21)$ & $4(11)$ & \\
\hline Missing & $6(8)$ & $4(11)$ & $2(5)$ & & $5(13)$ & $1(3)$ & \\
\hline $\mathrm{BMI}\left(\mathrm{kg} / \mathrm{m}^{2}\right)$ & & & & 0.82 & & & 0.67 \\
\hline Median & 24.9 & 24.9 & 24.8 & & 24.8 & 25.0 & \\
\hline IQR & $22.9-27.7$ & $22.9-27.3$ & $23.0-27.9$ & & $22.6-27.4$ & $23.1-27.9$ & \\
\hline Site of primary tumor & & & & 0.42 & & & 1.00 \\
\hline Colon & $58(77)$ & $31(82)$ & $27(73)$ & & $29(76)$ & $29(78)$ & \\
\hline Rectum & $17(23)$ & $7(18)$ & $10(27)$ & & $9(24)$ & $8(22)$ & \\
\hline No. of involved organs & & & & 0.38 & & & 0.58 \\
\hline 1 & $42(56)$ & $19(50)$ & $23(62)$ & & $19(50)$ & $23(62)$ & \\
\hline 2 & $23(31)$ & $12(32)$ & $11(30)$ & & $13(34)$ & $10(27)$ & \\
\hline$\geq 3$ & $10(13)$ & $7(18)$ & $3(8)$ & & $6(16)$ & $4(11)$ & \\
\hline Mutation & & & & 0.65 & & & 0.26 \\
\hline No mutation & $26(35)$ & $13(34)$ & $13(35)$ & & $12(32)$ & $14(38)$ & \\
\hline KRAS & $34(45)$ & $16(42)$ & $18(49)$ & & $16(42)$ & $18(49)$ & \\
\hline BRAF V600E & $5(7)$ & $2(6)$ & $3(8)$ & & $2(5)$ & $3(8)$ & \\
\hline Missing & $10(13)$ & $7(18)$ & $3(8)$ & & $8(21)$ & $2(5)$ & \\
\hline Pathology & & & & 0.79 & & & 0.76 \\
\hline Well & $6(8)$ & $3(8)$ & $3(8)$ & & $3(8)$ & $3(8)$ & \\
\hline Moderate & $51(68)$ & $25(66)$ & $26(70)$ & & $24(63)$ & $27(73)$ & \\
\hline Poor & $9(12)$ & $4(12)$ & $5(14)$ & & $5(13)$ & $4(11)$ & \\
\hline Missing & $9(12)$ & $6(16)$ & $3(8)$ & & $6(16)$ & $3(8)$ & \\
\hline Colorectal surgery & & & & 0.27 & & & 0.27 \\
\hline Yes & $58(77)$ & $27(71)$ & $31(84)$ & & $27(71)$ & $31(84)$ & \\
\hline No & $17(23)$ & $11(29)$ & $6(16)$ & & $11(29)$ & $6(16)$ & \\
\hline $\mathrm{CCl}$ & & & & 0.06 & & & 0.06 \\
\hline 0 & $2(3)$ & $0(0)$ & $2(6)$ & & $0(0)$ & $2(6)$ & \\
\hline 1 & $6(8)$ & $2(5)$ & $4(11)$ & & $2(5)$ & $4(11)$ & \\
\hline 2 & $24(32)$ & $12(32)$ & $12(32)$ & & $12(32)$ & $12(32)$ & \\
\hline 3 & $27(36)$ & $11(29)$ & $16(43)$ & & $11(29)$ & $16(43)$ & \\
\hline 4 & $13(17)$ & $10(26)$ & $3(8)$ & & $10(26)$ & $3(8)$ & \\
\hline$\geq 5$ & $3(4)$ & $3(8)$ & $0(0)$ & & $3(8)$ & $0(0)$ & \\
\hline Median & 3 & 3 & 3 & & 3 & 3 & \\
\hline IQR & $2-3$ & $2-4$ & $2-3$ & & $2-4$ & $2-3$ & \\
\hline
\end{tabular}

ECOG - Eastern Cooperative Oncology Group, PS - performance status, BMI - body mass index, IQR - interquartile range, CCI - Charlson comorbidity index 
Table 2. Treatment and dose intensity in the overall population and according to the relative dose intensity (RDI) of 5-fluorouracil (5-FU) and oxaliplatin or irinotecan (OXA-IRI)

\begin{tabular}{|c|c|c|c|c|c|c|c|}
\hline \multirow[t]{2}{*}{ Characteristics } & \multirow{2}{*}{$\begin{array}{l}\text { Overall } \\
n(\%)\end{array}$} & \multicolumn{3}{|c|}{ 5-FU RDI } & \multicolumn{3}{|c|}{ OXA-IRI RDI } \\
\hline & & $\begin{array}{l}\text { Low } \\
n(\%)\end{array}$ & $\begin{array}{l}\text { High } \\
n(\%)\end{array}$ & $p$-value & $\begin{array}{l}\text { Low } \\
n(\%)\end{array}$ & $\begin{array}{l}\text { High } \\
n(\%)\end{array}$ & $p$-value \\
\hline Number of patients & $75(100)$ & $38(51)$ & $37(49)$ & & $38(51)$ & $37(49)$ & \\
\hline Regimen & & & & 1.00 & & & 1.00 \\
\hline FOLFOX & $17(23)$ & $9(24)$ & $8(22)$ & & $9(24)$ & $8(22)$ & \\
\hline FOLFIRI & $58(77)$ & $29(76)$ & $29(78)$ & & $29(76)$ & $29(78)$ & \\
\hline Biologic therapy & & & & 0.37 & & & 0.37 \\
\hline Yes & $61(81)$ & $29(76)$ & $32(86)$ & & $29(76)$ & $32(86)$ & \\
\hline No & $14(19)$ & $9(24)$ & $5(14)$ & & $9(24)$ & $5(14)$ & \\
\hline Biologic therapy & & & & 0.49 & & & 0.46 \\
\hline Bevacizumab & $32(52)$ & $14(48)$ & $18(57)$ & & $15(52)$ & $17(53)$ & \\
\hline Cetuximab & $20(33)$ & $9(31)$ & $11(34)$ & & $8(28)$ & $12(38)$ & \\
\hline Panitumumab & $9(15)$ & $6(21)$ & $3(9)$ & & $6(20)$ & $3(9)$ & \\
\hline Number of cycles & & & & 0.04 & & & 0.19 \\
\hline Median & 10 & 12 & 6 & & 12 & 7 & \\
\hline$I Q R$ & $6-12$ & $6-12$ & $6-12$ & & $6-12$ & $6-12$ & \\
\hline Actual treat. duration (w) & & & & $<0.01$ & & & 0.02 \\
\hline Median & 24.6 & 26.7 & 13.3 & & 26.4 & 15.1 & \\
\hline $\mathrm{IQR}$ & $12.3-28.3$ & $14.5-28.8$ & $12.0-27.0$ & & $13.9-28.9$ & $12.1-27.3$ & \\
\hline Planned treat. duration (w) & & & & 0.04 & & & 0.19 \\
\hline Median & 20.0 & 24.0 & 12.0 & & 24.0 & 14.0 & \\
\hline $\mathrm{IQR}$ & $12.0-24.0$ & $12.5-24.0$ & $12.0-24.0$ & & $12.0-24.0$ & $12.0-24.0$ & \\
\hline Actual DI median (mg/w) & - & 1731.6 & 2185.0 & & 104.1 & 138.4 & \\
\hline Planned DI median (mg/w) & - & 2600.0 & 2506.0 & & 159.0 & 158.6 & \\
\hline
\end{tabular}

FOLFOX - leucovorin, 5-fluorouracil and oxaliplatin, FOLFIRI - leucovorin, 5-fluorouracil and irinotecan, IQR - interquartile range, DI - dose intensity, w-weeks

A

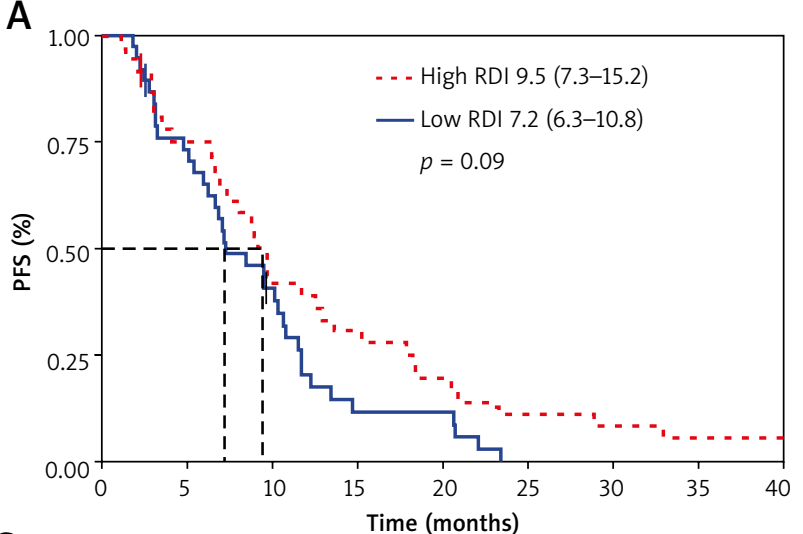

C

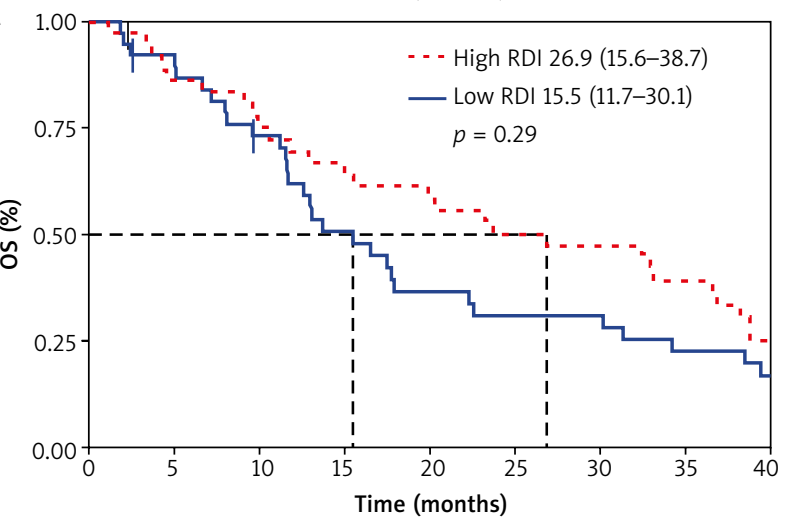

B

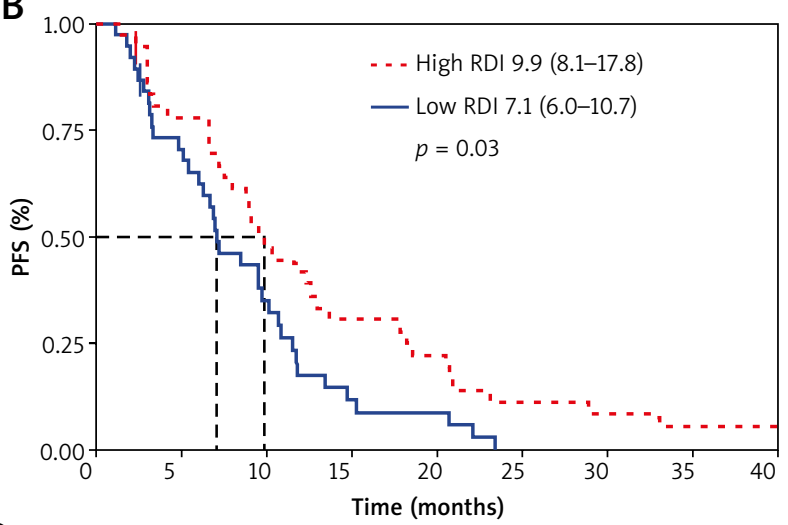

D

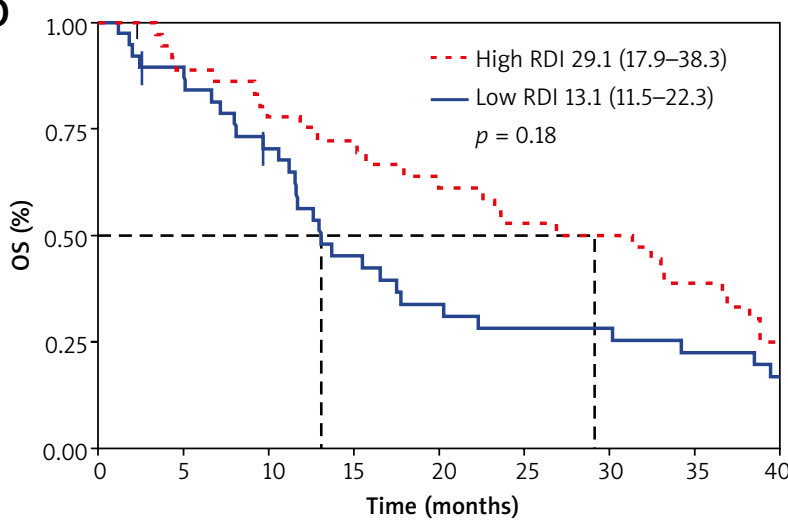

Fig. 1. Kaplan-Meier curves for survival. Caption: progression-free survival (A) for 5-FU, (B) for OXA-IRI, overall survival (C) for 5-FU, (D) for OXA-IRI. Medians are reported with a 95\% confidence interval 
Table 3. Univariate and multivariate analysis of progression-free survival

\begin{tabular}{|c|c|c|c|c|c|c|}
\hline \multirow[t]{2}{*}{ Characteristics } & \multicolumn{3}{|c|}{ Univariate analysis } & \multicolumn{3}{|c|}{ Multivariate analysis } \\
\hline & HR & $95 \% \mathrm{Cl}$ & $p$-value & HR & $95 \% \mathrm{Cl}$ & $p$-value \\
\hline \multicolumn{7}{|l|}{ Age } \\
\hline$<65$ vs. $\geq 65 y$ & 1.02 & $0.63-1.65$ & 0.94 & - & - & - \\
\hline \multicolumn{7}{|l|}{ Gender } \\
\hline Male vs. female & 0.89 & $0.54-1.44$ & 0.63 & - & - & - \\
\hline \multicolumn{7}{|l|}{ ECOG PS } \\
\hline $0-1$ vs. $2-3$ & 1.42 & $0.75-2.68$ & 0.28 & - & - & - \\
\hline \multicolumn{7}{|l|}{ BMI } \\
\hline$<25$ vs. $\geq 25 \mathrm{~kg} / \mathrm{m}^{2}$ & 0.77 & $0.48-1.24$ & 0.29 & - & - & - \\
\hline \multicolumn{7}{|l|}{ Site of primary tumor } \\
\hline Colon vs. rectum & 1.56 & $0.89-2.76$ & 0.12 & - & - & - \\
\hline \multicolumn{7}{|l|}{ No. of involved organs } \\
\hline 1 vs. 2 or more & 1.36 & $0.84-2.20$ & 0.21 & - & - & - \\
\hline \multicolumn{7}{|l|}{ Mutation } \\
\hline No mutation vs. KRAS & 0.97 & $0.56-1.66$ & 0.91 & 1.16 & $0.62-2.17$ & 0.64 \\
\hline No mutation vs. BRAF V600E & 17.30 & $5.20-57.60$ & $<0.01$ & 20.84 & $5.78-75.16$ & $<0.01$ \\
\hline \multicolumn{7}{|l|}{ Pathology } \\
\hline Well vs. moderate & 1.26 & $0.53-2.96$ & 0.60 & - & - & - \\
\hline Well vs. poor & 1.90 & $0.67-5.38$ & 0.23 & - & - & - \\
\hline \multicolumn{7}{|l|}{ Colorectal surgery } \\
\hline Yes vs. no & 0.54 & $0.30-0.96$ & 0.03 & 0.46 & $0.22-0.93$ & 0.03 \\
\hline \multicolumn{7}{|l|}{$\mathrm{CCl}$} \\
\hline$<4$ vs. $\geq 4$ & 1.12 & $0.63-1.98$ & 0.71 & - & - & - \\
\hline \multicolumn{7}{|l|}{ Regimen } \\
\hline FOLFOX vs. FOLFIRI & 0.98 & $0.54-1.78$ & 0.96 & - & - & - \\
\hline \multicolumn{7}{|l|}{ Biologic therapy } \\
\hline Yes vs. no & 1.39 & $0.86-2.25$ & 0.18 & - & - & - \\
\hline
\end{tabular}

ECOG - Eastern Cooperative Oncology Group, PS - performance status, BMI - body mass index, CCl-Charlson comorbidity index, FOLFOX - leucovorin, 5-fluorouracil and oxaliplatin, FOLFIRI - leucovorin, 5-fluorouracil and irinotecan

the multivariate analysis. Body mass index, chemotherapy regimen and biologic therapy were predictive of overall survival but only in the univariate analysis. Initial performance status and Charlson comorbidity index had no impact on progression-free survival or overall survival.

\section{Toxicity}

The toxicity profile of the patients is presented in Table 5. Nausea and vomiting were the most frequent toxicity effects (37\% of the patients) followed by diarrhea (32\%) and neuropathy (19\%). The majority of toxicities (91\%) were grade I or II, grades III or IV accounting only for $8 \%$ of toxicities. No statistically significant difference was observed according to the RDI.

\section{Discussion}

For oxaliplatin and irinotecan, our study on real-life patients showed a significant link between RDI and PFS. These results are consistent with the work of Nakayama et al. and Maindrault-Goebel et al., whose analysis focused on patients from clinical trials $[12,13]$. Several models have been proposed to explain the relationship between dose intensity/density of chemotherapy and tumor growth [19]. In Norton's model, the higher the density, the more limited is the tumor re-growth between cycles [20]. However, our analysis did not find an impact on OS of low RDI of 5-FU or OXA-IRI.

In our cohort, the median RDI was $78.3 \%$ for both 5-FU and OXA-IRI. In clinical trials with FOLFOX and FOLFIRI, the RDIs are often higher, for example up to $92 \%$ for 5 -FU, $87.8 \%$ for oxaliplatin and $93 \%$ for irinotecan $[1,3,4]$. This difference is likely because patients in clinical trials are typically younger, healthier, and better able to withstand higher does intensities than patients from real-life.

In addition, there is a significantly longer treatment duration for patients with low RDI, associated with a higher number of cycles. This could be explained by a better tolerance to treatment in patients with a low RDI, i.e. patients whose dose has been reduced or cycles delayed, allowing more cycles to be administered.

Our analysis identified the BRAF V600E mutation and colorectal surgery as independent factors for progression-free survival and overall survival. A recent meta-analysis of nearly 160,000 patients showed a significant effect 
Table 4. Univariate and multivariate analysis of overall survival

\begin{tabular}{|c|c|c|c|c|c|c|}
\hline \multirow[t]{2}{*}{ Characteristics } & \multicolumn{3}{|c|}{ Univariate analysis } & \multicolumn{3}{|c|}{ Multivariate analysis } \\
\hline & $\mathrm{HR}$ & $95 \% \mathrm{Cl}$ & $p$-value & $\mathrm{HR}$ & $95 \% \mathrm{Cl}$ & $p$-value \\
\hline \multicolumn{7}{|l|}{ Age } \\
\hline$<65$ vs. $\geq 65$ years & 1.19 & $0.73-1.93$ & 0.47 & - & - & - \\
\hline \multicolumn{7}{|l|}{ Gender } \\
\hline Male vs. female & 1.18 & $0.73-1.92$ & 0.50 & - & - & - \\
\hline \multicolumn{7}{|l|}{ ECOG PS } \\
\hline $0-1$ vs. 2-3 & 1.38 & $0.72-2.66$ & 0.33 & - & - & - \\
\hline \multicolumn{7}{|l|}{ BMI } \\
\hline$<25$ vs. $\geq 25 \mathrm{~kg} / \mathrm{m}^{2}$ & 0.57 & $0.35-0.92$ & 0.02 & 0.87 & $0.46-1.65$ & 0.67 \\
\hline \multicolumn{7}{|l|}{ Site of primary tumor } \\
\hline Colon vs. rectum & 1.53 & $0.87-2.67$ & 0.14 & - & - & - \\
\hline \multicolumn{7}{|l|}{ No. of involved organs } \\
\hline 1 vs. 2 or more & 1.33 & $0.83-2.15$ & 0.24 & - & - & - \\
\hline \multicolumn{7}{|l|}{ Mutation } \\
\hline No mutation vs. KRAS & 0.70 & $0.40-1.22$ & 0.21 & 0.78 & $0.40-1.52$ & 0.46 \\
\hline No mutation vs. BRAF V600E & 8.56 & $2.80-26.17$ & $<0.01$ & 4.01 & $1.15-13.90$ & 0.03 \\
\hline \multicolumn{7}{|l|}{ Pathology } \\
\hline Well vs. moderate & 1.29 & $0.55-3.02$ & 0.56 & 1.30 & $0.34-4.87$ & 0.70 \\
\hline Well vs. poor & 4.51 & $1.55-13.16$ & $<0.01$ & 4.71 & $1.01-21.89$ & 0.04 \\
\hline \multicolumn{7}{|l|}{ Colorectal surgery } \\
\hline No vs. yes & 0.33 & $0.18-0.59$ & $<0.01$ & 0.24 & $0.09-0.65$ & 0.01 \\
\hline \multicolumn{7}{|l|}{$\mathrm{CCl}$} \\
\hline$<4$ vs. $\geq 4$ & 1.03 & $0.57-1.85$ & 0.93 & - & - & - \\
\hline \multicolumn{7}{|l|}{ Regimen } \\
\hline FOLFOX vs. FOLFIRI & 0.52 & $0.28-0.95$ & 0.03 & 1.44 & $0.41-5.07$ & 0.57 \\
\hline \multicolumn{7}{|l|}{ Biologic therapy } \\
\hline Yes vs. no & 1.91 & $1.06-3.48$ & 0.04 & 2.04 & $0.59-7.04$ & 0.26 \\
\hline
\end{tabular}

ECOG - Eastern Cooperative Oncology Group, PS - performance status, BMI - body mass index, CCI - Charlson comorbidity index, FOLFOX - leucovorin, 5-fluorouracil and oxaliplatin, FOLFIRI-leucovorin, 5-fluorouracil and irinotecan

on survival of primary tumor resection in patients with localized incurable or mCRC [21].

There are several limitations of our study. First of all, due to the limited number of patients in our center, we decided to study the impact of RDI of oxaliplatin and irinotecan on survival in an undifferentiated way, in an OXA-IRI group. The effect of RDI on survival for each molecule could therefore not be determined. In the analysis of Nakayama et al., only high RDI of irinotecan had a significant impact on PFS [12]. The improvement in PFS in the OXA-IRI group in our study could be explained by a higher proportion of patients who received irinotecan (71\%) instead of oxaliplatin. A second limitation is represented by a probable confounding factor which consists of reducing the doses of chemotherapy or in spacing out the cycles in patients who become clinically impaired. The poorer survival could be explained by clinical deterioration and not by the reduction in RDI. Finally, hematological toxicity is likely underestimated in our cohort due to missing data.

\section{Conclusions}

Our analysis suggests that a low RDI of oxaliplatin or irinotecan has a negative impact on PFS in patients treat- ed in real-life for a mCRC with FOLFOX or FOLFIRI. However, RDI had no significant effect on OS in our cohort. Based on this last observation, it seems unreasonable to try to maintain a high RDI, with a greater risk of toxicity, in palliative patients whose quality of life should be maintained as long as possible.

\section{Acknowledgments}

We thank Sébastien Pirson and Kristine Smith Herbomel for revising English grammar and style.

The authors declare no conflict of interest.

\section{References}

1. Douillard JY, Cunningham D, Roth AD, Navarro M, James RD, Karasek P, Jandik P, Iveson T, Carmichael J, Alakl M. Irinotecan combined with fluorouracil compared with fluorouracil alone as first-line treatment for metastatic colorectal cancer: a multicentre randomised trial. Lancet 2000; 355: 1041-1047.

2. Saltz LB, Cox JV, Blanke C, et al. Irinotecan plus Fluorouracil and Leucovorin for Metastatic Colorectal Cancer. N Engl J Med 2000; 343: 905-914. 
Table 5. Toxicity in the overall population and according to the relative dose intensity (RDI) of 5-fluorouracil (5-FU) and oxaliplatin or irinotecan (OXA-IRI)

\begin{tabular}{|c|c|c|c|c|c|c|c|}
\hline \multirow[t]{2}{*}{ Characteristics } & \multirow{2}{*}{$\begin{array}{c}\text { Overall } \\
n(\%)\end{array}$} & \multicolumn{3}{|c|}{ 5-FU RDI } & \multicolumn{3}{|c|}{ OXA-IRI RDI } \\
\hline & & $\begin{array}{l}\text { Low } \\
n(\%)\end{array}$ & $\begin{array}{l}\text { High } \\
n(\%)\end{array}$ & $p$-value & $\begin{array}{l}\text { Low } \\
n(\%)\end{array}$ & $\begin{array}{l}\text { High } \\
n(\%)\end{array}$ & $p$-value \\
\hline Number of patients & $75(100)$ & $38(51)$ & $37(49)$ & & $38(51)$ & $37(49)$ & \\
\hline Toxicity & & & & 0.48 & & & 0.96 \\
\hline Yes & $64(85)$ & $34(90)$ & $30(81)$ & & $33(87)$ & $31(84)$ & \\
\hline No & $11(15)$ & $4(10)$ & 7 (19) & & $5(13)$ & $6(16)$ & \\
\hline Toxicity grade & & & & 1.00 & & & 1.00 \\
\hline $1-2$ & $68(91)$ & $34(89)$ & $34(92)$ & & $35(92)$ & 33 (89) & \\
\hline $3-4$ & $6(8)$ & $3(8)$ & $3(8)$ & & $3(8)$ & $3(8)$ & \\
\hline Missing & $1(1)$ & $1(3)$ & $0(0)$ & & $0(0)$ & $1(3)$ & \\
\hline Non-hematological & $61(81)$ & $33(87)$ & $28(76)$ & 0.35 & & & 0.73 \\
\hline Nausea and vomiting & $28(37)$ & $12(32)$ & $16(43)$ & & $14(37)$ & $14(38)$ & \\
\hline Diarrhea & $24(32)$ & $14(37)$ & $10(27)$ & & $12(32)$ & $12(32)$ & \\
\hline Neurotoxicity & $14(19)$ & $7(18)$ & 7 (19) & & 7 (18) & $7(19)$ & \\
\hline Mucositis & $13(17)$ & $6(16)$ & 7 (19) & & $6(16)$ & 7 (19) & \\
\hline Kidney injury & $3(4)$ & $3(8)$ & $0(0)$ & & $3(8)$ & $0(0)$ & \\
\hline Hand-foot syndrome & $2(3)$ & $2(5)$ & $0(0)$ & & $1(3)$ & $1(3)$ & \\
\hline Hematological & $10(13)$ & $4(11)$ & $6(16)$ & 1.00 & $4(11)$ & $6(16)$ & 1.00 \\
\hline Neutropenia & $8(11)$ & $3(8)$ & $5(14)$ & & $3(8)$ & $5(14)$ & \\
\hline Thrombocytopenia & $2(3)$ & $1(3)$ & $1(3)$ & & $1(3)$ & $1(3)$ & \\
\hline
\end{tabular}

3. Rothenberg ML, Oza AM, Bigelow RH, et al. Superiority of Oxalipla tin and Fluorouracil-Leucovorin Compared With Either Therapy Alone in Patients With Progressive Colorectal Cancer After Irinotecan and Fluorouracil-Leucovorin: Interim Results of a Phase III Trial. J Clin Oncol 2003; 21: 2059-2069.

4. de Gramont A, Figer A, Seymour M, et al. Leucovorin and fluorouracil with or without oxaliplatin as first-line treatment in advanced colorectal cancer. I Clin Oncol 2000; 18: 2938-2947.

5. Tol J, Punt CJA. Monoclonal antibodies in the treatment of metastatic colorectal cancer: A review. Clin Ther 2010; 32: 437-453.

6. Thibault V, Leguelinel-Blache G, Obled S, et al. [Chemotherapy for colorectal cancer: Pragmatic assessment of prescription changes and relative dose intensity]. Bull Cancer (Paris) 2017; 104: 714-720.

7. Hryniuk WM. The importance of dose intensity in the outcome of chemotherapy. Important Adv Oncol 1988: 121-141.

8. Lyman GH. Impact of chemotherapy dose intensity on cancer patient outcomes. J Natl Compr Cancer Netw 2009; 7: 99-108.

9. Loibl S, Skacel T, Nekljudova V, et al. Evaluating the impact of Relative Total Dose Intensity (RTDI) on patients' short and longterm outcome in taxane- and anthracycline-based chemotherapy of metastatic breast cancer- a pooled analysis. BMC Cancer 2011; 11: 131

10. Budman DR, Berry DA, Cirrincione CT, et al. Dose and Dose Intensity as Determinants of Outcome in the Adjuvant Treatment of Breast Cancer. J Natl Cancer Inst 1998; 90: 1205-1211.

11. Denduluri N, Lyman GH, Wang Y, et al. Chemotherapy Dose Intensity and Overall Survival Among Patients With Advanced Breast or Ovarian Cancer. Clin Breast Cancer 2018; 18: 380-386.

12. Nakayama G, Tanaka C, Uehara K, et al. The impact of dose/time modification in irinotecan- and oxaliplatin-based chemotherapies on outcomes in metastatic colorectal cancer. Cancer Chemother Pharmacol 2014; 73: 847-855.

13. Maindrault-Goebel F, de Gramont A, Louvet C, et al. Evaluation of oxaliplatin dose intensity in bimonthly leucovorin and 48-hour 5-fluorouracil continuous infusion regimens (FOLFOX) in pretreated metastatic colorectal cancer. Oncology Multidisciplinary Research Group (GERCOR). Ann Oncol 2000; 11: 1477-1483.
14. Hryniuk WM, Figueredo A, Goodyear M. Applications of dose in tensity to problems in chemotherapy of breast and colorectal cancer. Semin Oncol 1987; 14 (Suppl 4): 3-11.

15. Cascinu S, Fedeli A, Luzi-Fedeli S, Catalano G. 5-Fluorouracil Dose Intensity Increase in 5-Fluorouracil and Leucovorin Combination: Results of a Phase II Study. J Chemotherapy 1991; 3: 51-54.

16. Munker S, Gerken M, Fest P, et al. Chemotherapy for metastatic colon cancer: No effect on survival when the dose is reduced due to side effects. BMC Cancer 2018; 18: 455.

17. Mochinaga S, Okahashi T, Koga S, et al. Effects of reduced dose intensity of modified FOLFOX6 in patients with metastatic or recurrent colorectal cancer. Oncol Res 2011; 19: 511-518.

18. Charlson ME, Pompei P, Ales KL, Mackenzie CR. A new method of classifying prognostic comorbidity in longitudinal studies: development and validation. J Chronic Dis 1987; 40: 373-383.

19. Foote M. The Importance of Planned Dose of Chemotherapy on Time: Do We Need to Change Our Clinical Practice? Oncologist 1998; 3: 365-368.

20. Norton L. A Gompertzian Model of Human Breast Cancer Growth. Cancer Res 1988; 48: 7067-7071.

21. Simillis C, Kalakouti E, Afxentiou T, et al. Primary Tumor Resection in Patients with Incurable Localized or Metastatic Colorectal Cancer: A Systematic Review and Meta-analysis. World J Surg 2019; 43. $1829-1840$

\section{Address for correspondence}

\section{Ilfad Blazevic}

Medical Oncology Department

University Cancer Institute Toulouse Oncopole

1 Avenue Irène Joliot-Curie

31100 Toulouse, France

e-mail: ilfad.blazevic@gmail.com

Submitted: 8.05.2020

Accepted: 30.06.2020 